\title{
Indicators of Marital Satisfaction of Batangueño Couples: Components of Love and the Other External Factors in Marriage
}

\author{
Madonna Nympha S. Carandang and Isabel Vivien P. Guda
}

\begin{abstract}
This study dealt with the correlation between the levels of Sternberg's components of love (intimacy, passion and commitment) and the level of marital satisfaction of selected married couples in Batangas. Moreover, the levels of components of love and levels of marital satisfaction based on the varying profile of the respondents are compared. A survey method using questionnaires (Triangular Theory of Love Scale (TTLS) and Couples Satisfaction Index (CSI-32)) translated in Filipino language were used to collect the data. There were 400 married couples who participated in the study. The result of the correlational analysis revealed a very strong positive and significant relationship between the level of intimacy and marital satisfaction of both male and female respondents, while strong positive and significant relationships on levels of passion and commitment and level of marital satisfaction of the male and female respondents. Furthermore, several significant differences are enumerated: a) on the level of intimacy of the male respondents when they were grouped according to their age of marriage; b) on the level of passion of the male respondents when they were grouped according to their employment status; c) on the level of commitment of the respondents based on educational attainment of female respondents and employment status of both male and female respondents; and d) on the level of marital satisfaction of the male respondents when they were grouped according to their employment status. Practical implications of the findings were discussed.
\end{abstract}

Index Terms-Commitment, intimacy, marital satisfaction, passion.

\section{INTRODUCTION}

Marital success is the goal and dream of every couple upon entering the married life though such is a real challenge. Thus, considering several vital factors contributing to it and gaining knowledge on how to build a strong and successful marital relationship are good starting points to achieve such goal.

Philippines is a nation of friendly people; very good in maintaining close relationship. As individuals, Filipinos have close family ties, can easily make friends with others, and are able to establish close interpersonal and intimate relationship. Certainly, such connections are expected to last for good.

Manuscript received September 29, 2013; revised January 22, 2014 This research was written in partial fulfillment of the requirement for the degree Bachelor of Science in Psychology.

Madonna Nympha S. Carandang was with De La Salle Lipa, Batangas 4217 Philippines (e-mail: mnscarandang16@yahoo.com).

Isabel Vivien P. Guda was with De La Salle Lipa, Batangas 4217 Philippines (e-mail: ivpguda92@yahoo.com).
Unfortunately, these days, it is apparent that little by little, Filipino broken families are increasing in number.

The love which used to bind people together eventually diminishes leading to separation of couples and destruction of families. The goal of achieving marital success appears to be close to impossible but with thorough studies of the various factors regarding love and relationship, this sad reality may be remedied.

Clearly, love plays a significant role in maintaining a close interpersonal relationship on people's lives. People yearn for it, live for it, die for it. Paul Webster, in his "Love is a Many Splendored Thing", stated that "Love is nature's way of giving a reason to be living" [1]. With the emergence of various theories of love, understanding it proved to be truly significant and less complicated than what most psychologists and researchers think about it as it seems to be perplex and impossible to explain.

However, the world constantly in flux has altered the view of people regarding love in a relationship. The bond, believed to be strengthened solely by love before is perceived to be greatly affected now by various external factors inevitable in a relationship. Thus, taking into consideration all the external factors that may have played in the process of love can shed light on the vague understanding of people regarding this phenomenon. After all, this is one of the main concerns of every society wherein relationships appear to fall apart little by little.

Particularly, there are approximately 593,553 married couples in the Philippines [2]. Moreover, as reported by Dela Cruz in 2008, the number of annulment marriage filed in the Philippines greatly increased to 7,753 in 2008 based from data on marriages obtained by the National Statistics Office (NSO) [3]. This indicates that there is a need to strengthen marital relationship.

Thus, using the western theory, Sternberg's Triangular Theory of Love by Robert Sternberg, the local society's state of marital relationship is uncovered by assessing the love components, namely intimacy, passion and commitment [4]. Consequently, marital satisfaction will be determined through a self report scale called the Couples Satisfaction Index (CSI-32) developed by Janette L. Funk and Ronald D. Rogge. CSI-32 is believed to be more precise, more accurate and is able to provide greater amounts of information as compared to other existing measures of marital satisfaction [5].

The meaning of love and how it is perceived varies from one person to another. This is the reason why satisfaction experienced differs according to the persons involved in a marital relationship. Married couples may find love but it is uncertain whether that love will provide lasting relationship, 
and thus, satisfaction during the relationship is important as much as being in love. With the understanding of the various factors contributing to marital relationship and how love and satisfaction contribute to the stability and strength of the relationship, this study hopes to help strengthen the foundation of marital relationship by uncovering the vital information that will provide better solutions to preserve marital relationships and the close family ties of the Filipinos in the province of Batangas. The indication of this study will also inspire to give feedback to other married couples and those who are engaged to enter marriage.

\section{REVIEW OF RELATED LITERATURES AND STUDIES}

\section{A. Marriage}

Marriage is generally defined as "a social contract between two individuals that unites their lives legally, economically, and emotionally" that gives legitimacy to sexual relations within the marriage [6]. It may also refer to the union between people, regardless of the legality, which unites partners sexually, socially, and economically. Scott and Schwartz stressed that the said union in marriage is relatively consistent over time and accords each member certain agreed-upon rights.

For Filipinos, a unique and distinct belief that "courtship is long, engagement is short and marriage is lasting," and resistance to divorce are influenced by religion specifically Catholicism which is predominant in the Philippines. According to Cruz in 2008, marriage is "a covenant between a man and a woman who thereby establish a partnership between themselves" from the understanding of the Catholic Church. Hence, marriage transcends from being ritualistic ceremony including marital vows that transforms the relationship into a social fiber that connects individuals regardless of their ethnic differences [3].

\section{B. Love and its Components}

In the attempt to study close relationships between individuals, various theories regarding love have emerged in the past decades. In 1988, Robert Sternberg presented a "triangular theory" of love [see theoretical framework] wherein the relationships of the kinds of love discussed by many theorist were organized [7]. Seeking an integration of actions into love in order to maximize happiness, this theory positively imply relationship satisfaction based on the research of Tang Pui Tung in 2007 wherein love components are all positively related to the relationship satisfaction experienced by couples. Apparently, Sternberg presents the love components on a triangle but it does not assure the balance among the three components. Sternberg (1986) suggests that greater discrepancy among the three components is associated with lesser satisfaction in the relationship [8].

The Triangular Theory of Love is consisted of three components namely intimacy, passion and commitment, which will be discussed further in the succeeding paragraphs.

\section{Intimacy}

Intimacy involves the feelings of closeness and connectedness toward another person which removes psychological boundaries between people and brings about the desire to share one's innermost thoughts with the other [7]. According to Erickson (1950), establishment of intimacy is the central task of a young adult [9] wherein one acts considering some or all aspects of the partner thus expanding one's self-concept, an indicator of the level of relationship intimacy [10].

Founded self-concept helps a person evaluate self worth (self-esteem), identify own feelings and needs and develop the security to share them to facilitate initial step toward intimacy with other. According to Murray and his colleagues, when doubts arise, people with high self-esteem maintain their self worth by using their partner's acceptance and approval while those people (e.g. young people who married in search for their identity) with low self-esteem harbor hostility and feelings of rejection [11] Too much self-esteem however, in the form of narcissism, or being wrapped up in oneself can also be detrimental to a relationship [7]. Thus, unbalanced level of self-esteem brings about a sense of being underbenefitted which based on the research of Susan Sprecher (2001) is correlated to lower satisfaction, lesser commitment, and a higher likelihood of breaking up [9].

In building intimate relationship, making sacrifices is important to produce feelings of trust, care, and acceptance according to Rusbult and van Lange (2003). Based from the research of Van Lange et al. (1997), it was found that "willingness to sacrifice is connected with commitment to relationship, level of satisfaction in the relationship, and, interestingly, poor alternatives to the relationship." Hence, Katz and Tirone (2009) asserted that finding a partner will not be easy if one does not sacrifice for relationships [7].

\section{Passion}

Passion refers to the intense emotions accompanied by physiological arousal and persistent strong sexual desire wherein a person experience feelings of longing and excitement for a special person. Furthermore, passionate love is characterized as couple's emphasis on being great lovers, volatility of relationship and domination of the partner's life. It is the kind of love that drive people to think about each other, spend as much time as possible together, touch each other and engage in other physical intimacies (often including sex), and exhibit other patterns that suggests strong emotions such as jealousy [9], [7], [12]. Barber (2002) and Kurup \& Kurup (2003) considered that these behaviors displayed with focused attention, concentrated motivation to attain a reward, and a sense of giddiness are primarily fueled by dopamine, one of nature's most powerful stimulants that changes the chemistry of the brain [10].

Passionate love is considered as an enemy of a lasting marital love because it does not and cannot last indefinitely [9]. Research showed that the initial passion of a new relationship fades within six to thirty months [13]. In addition, Crosby in 1991 asserted that the idealistic expectations of bliss created by the emphasis on passionate love can lead to a considerable amount of "misery, disappointment, and disillusionment" in marriage or longterm relationships.

Apparently, in the Eastern societies, men place more significance on sexuality in a relationship, making them 
more emotionally dependent on the spouse. Moreover, Anonuevo (2009) claimed that patriarchal system is evident in the Philippine culture [14]. With this, culture dictates that men be permissive to their partner, and act as the breadwinner. Similarly, women are expected to become less sexually permissive but friendlier when it comes to intimate relationships. Culture imbibed on women to choose a partner who can support a living. Thus, a woman's choice is often practical [15].

\section{E. Commitment}

According to Sternberg (2004), commitment which maintains the relationship through thick and thin marks intimate relationships. It is developed collectively with trust in a relationship based on the model of mutual cyclical growth. This model explains that feelings needed by one partner promote commitment to and dependence on the relationship. This commitment to the relationship encourages the partners to perform "pro-relationship acts" or the things which are good for the relationship. When one perceived "pro-relationship acts", his or her trust in the partner and in the relationship will be enhanced. The partners' willingness to depend on the relationship will increase with this feeling of trust [4].

Commitment signifies "a promise of dedication to a relationship in which there is an emotional attachment to another person who has made the same promise" as quoted by Lauer and Lauer (1986). According to Quinn in 1982 and Weigel, Bennett, \& Ballard-Reisch in, promise, dedication, and attachment, for Americans are the three constituents that give meaning to commitment in marriage [9]. Promise or pledge such as "for better or for worse" of the traditional wedding vow engages the couple in something that will include some difficult times whereas dedication joins the goal of a couple of staying together and forming a meaningful family unit. The combined dedication of the couple's aim becomes the source of emotional attachment of two people. Furthermore, commitment also gives the partners a sense of security wherein one regards jealousy as his or her own problem and not the fault of his or her partner for he or she knows that they are committed to each other [9].

Couples who are committed to each other [work through troubled times] resulted to long-term satisfying marriages while couples who are committed to the institution of marriage (endure troubled times) have long-term but unsatisfying union. Those who work out problems, rather than endure or wait them out, find the quality of their relationship greatly enhanced [9]. Those couples, who have fewer marriage problems, express their love for their partners more often, and have higher levels of marital satisfaction are said to be committed to their spouse as persons (Swensen \& Trahaug 1985 and Clements \& Swensen 2000) [9]. Hence, commitment is a vital resource in the enrichment of marital relationship.

\section{F. Marital Satisfaction}

In a general sense, satisfaction in life is grounded most of the time on the expectations that one has and how well these expectations matches with what is being experienced by a person [15]. Satisfaction in a marital relationship also has the same grounds.
According to Cox [15], if a person is free to create the kind of marital relationship he or she desires, then it implies that he or she is responsible for the outcome of the relationship, be it a success or failure. Scott and Schwartz suggest that despite the increase in the divorce or separation rate on relationships, which are believed to be indicators of the decline of marital success, many couples still claim that they are happily married and if given the chance to marry again, they will marry the same person.

Marital success, the main goal of every marital relationship, is defined as something incorporated with adjustment, happiness and permanence. Thus, if the partners can adjust to each other and with the relationship, the couple agrees with each other most of the time in the significant issues in their lives, the partners are eased with their roles in their relationship and they can overcome the problems and troubles that come their way, then the relationship can be considered a successful marriage. When each partner can freely express satisfaction with each other, then there is a great possibility that the marriage will last. So, for marital success to be achieved, marital adjustment, permanence and happiness are required. An absence of even a single component will affect the quality of the marital relationship. Hence, these concepts, despite being distinct from each other, are all significant in describing success in a marital relationship [15].

In addition, several other researches were done to investigate on other factors which can affect and influence the marital relationship of couples.

\section{RESEARCH FRAMEWORK}

\section{A. Theoretical Framework}

This study (see Fig. 1) is anchored on Robert Sternberg's Triangular Theory of Love, holding that love can be understood in terms of three components. A triangle was used as a metaphor model for the three components of love forming the three vertices which may be arbitrary: Intimacy (top vertex), passion (left vertex) and decision or commitment (right vertex) [4].

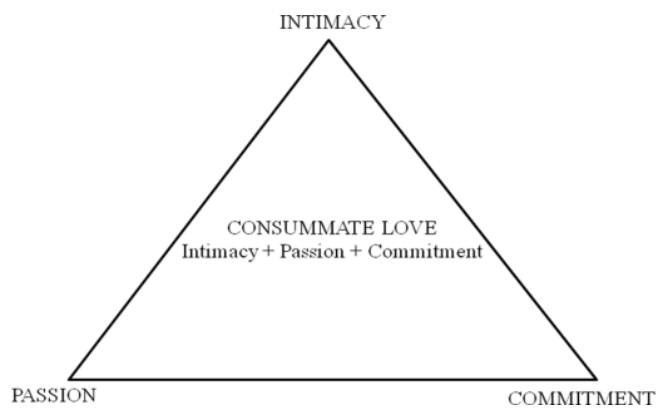

Fig. 1. Theoretical framework.

These three components of love interact with each other, though separable. Although all the components are important parts of a loving relationship, their importance differ from one relationship to another, or over time within a given relationship. Sternberg (1986) suggests that the higher the level of components of love, the greater the experienced love is [4]. The area of each component in Sternberg's triangle of love is essential in order to improve 
relationship; hence, the three components must be combined to achieve consummate love. In connection to this, Sternberg developed a Triangular Love Scale, a test used to measure the levels of the three components of love.

\section{Methodology}

\section{A. Research Design}

The researchers made use of descriptive method of research using comparative correlational design to figure out the differences on the levels of components of love and marital satisfaction in terms of the varying profile of the respondents of the study so as the relationship between the constructs.

\section{B. Sources of Data}

Self report measures such as the Triangular Theory of Love Scale (TTLS) and Couples Satisfaction Index (CSI-32) served as the primary source of data while books, journals and thesis were also be utilized for this study as the secondary source. Moreover, the documents of the government covering the respondents of the study, and published materials like journals and unpublished materials like thesis and articles from various reliable internet websites were also used. Interview was also conducted by the researchers to validate the data obtained from the respondents.

\section{Sampling Design}

The researchers made use of a probability sampling technique, particularly, proportionate stratified random sampling, to ascertain that each of the subgroup or municipality or stratum covered in the study will have a representation or sample taken from it.

\section{Respondents and Locale of the Study}

The respondents of the study were selected married couples residing at Batangas City District III regardless of their profile. This covers the municipalities of Agoncillo, Alitagtag, Balete, Cuenca, Laurel, Malvar, Mataas na Kahoy, San Nicolas, Sta. Teresita, Sto. Tomas and Talisay.

The respondents for the study were legally wed couples, whose marriage was monogamous. Cohabitating couples were not included also. Moreover, it is but necessary that the couples live together, thus, those who have spouses away were excluded in the study. The criteria for the respondents were set to ensure that the population is well represented and the purpose of the study is met.

Out of 422, 050 total numbers of households on the eleven municipalities belonging in the third legislative district of Batangas, 800 individual respondents or 400 couples represented the overall population. The researchers supposed that every household has a couple since there is no other way to accurately obtain the total number of couples residing on the research locale [16].

\section{E. Research Tools and Instruments}

Triangular Theory Love Scale is a 45-item scale designed to measure the three components of love. Thus, each component is represented by 15 item subscale intended to assess it. Each scale is rated on 9-point Likert scales (1=not at all, 5=moderately, 9=absolutely). The scores in the 15 items for each component are to be summed up to come up with the interpretation of the scores. High scores in all the three components indicate consummate love while uneven or low scores have the implication that the relationship is not that strong [4]. According to Tzeng (1993), TTLS (See Table I) is found to have high internal consistency, alpha coefficients for three subscales are above 0.90 [8].

TABLE I: SCORING SYSTEM USED IN STERNBERG'S TRIANGULAR THEORY OF LOVE SCALE

\begin{tabular}{|c|c|c|c|}
\hline $\begin{array}{c}\text { I } \\
(1-15)\end{array}$ & $\begin{array}{c}\text { P } \\
(16-30)\end{array}$ & $\begin{array}{c}\text { C } \\
(31-45)\end{array}$ & $\begin{array}{c}\text { Verbal } \\
\text { Interpretation }\end{array}$ \\
\hline 93 & 73 & 85 & $\begin{array}{c}\text { Significantly below } \\
\text { ave. }\end{array}$ \\
\hline 102 & 85 & 96 & Somewhat below ave. \\
\hline 111 & 98 & 108 & Average \\
\hline 120 & 110 & 120 & Somewhat above ave. \\
\hline 129 & 123 & 131 & $\begin{array}{c}\text { Significantly above } \\
\text { ave. }\end{array}$ \\
\hline
\end{tabular}

Source: Robert Sternberg (1988)

Legends: I-Intimacy; P-Passion; C-Commitment; Ave-Average

On the other hand, the Couples Satisfaction Index (CSI32), developed by Janette L. Funk and Ronald D. Rogge, was used to assess the level marital satisfaction experienced by couples. In the study done by Funk and Rogge, it was revealed that compared to the traditional scales used to assess marital satisfaction, CSI scales demonstrated higher precision of measurement and greater power for detecting differences in the levels of satisfaction. Having gone through item-level analysis for evaluation of the current level of precision, CSI scales turned out to be more than a simple self report measure. Therefore, this is a guarantee that CSI actually assesses solely the quality of satisfaction felt by couples involved in a relationship, and is not influenced by other possible confounding variance from constructs like communication.

The CSI scales demonstrate excellent internal consistency, and with the Cronbach alpha coefficient of .98. It also has strong convergent validity with other measures of satisfaction, from which the scale was developed. Moreover, it was found out that CSI scales also have patterns of associations with the anchor scales which are somewhat similar to those of the existing measures of satisfaction, implying that CSI scales can be considered a conceptual equivalent to the other instrument measuring the same construct. Likewise, it has excellent construct validity with anchor scales from nomological net surrounding satisfaction, suggesting that they assess the same theoretical construct as do the other scales.

As for the scoring and interpretation of the test, the score that could be obtained ranges from zero to 161 . The dissatisfaction cut off score is 104.5. This implies that those whose scores were below 104.5 are dissatisfied in their marital relationship while those whose scores were higher than 104.5 are satisfied in their marital relationship [5].

\section{F. Data Gathering Procedure}

The researchers sent a letter of request to the representative of each municipal government comprising the District III of Batangas. The approval of this letter served as the researchers' permit to start conducting the study in the respective municipalities, administering the tests, and doing the interview on the selected respondents on the locale. The 
researchers gave the questionnaires translated in Filipino for the respondents' convenience.

For the convenience of the respondents, the two tests are translated to Filipino language with the help of one of the faculty of Literature and Arts Department of De La Salle Lipa. After that, the researchers proceeded to the pilot testing to verify the validity and reliability of the tests despite the translation. The respondents for the pilot testing were 55 couples residing at Labac, Cuenca. The process yield high and acceptable reliability and validity for both tests. The CSI scales have the Cronbach alpha of .924 for female while it is .907 for male. On the other hand, the TTLS have the Cronbach alpha of .976 for female while it is .972 for male.

The researchers administered the tests after the approval of the Mayor of all District III municipalities, then Head of Municipal Social Welfare Department (MSWD) or Chairperson of Baranggay of the sample population. They oriented the respondents on how to answer the tests. There is the need for the tests to be left since it is impossible for both couples to be present by the time the researchers are in their respective municipalities. However, in some cases, the researchers observe the respondents as they answer the tests. Selected couples were also interviewed to validate the data obtained through primary data collection.

\section{RESUlTS AND CONCLUSION}

Most of the male respondents are aged 43 to 54 while most of the female respondents are within 29 to 40 years old. Thus, majority of the respondents are middle aged persons. Likewise, majority of the male respondents got married when they were 27 to 36 years old, while a large number of the female respondents got married younger than male at the age of 23 to 30 years old. These findings regarding marrying age oppose the literature asserting that today's adults are delaying marriage, due to several factors such as educational attainment and economic level [17]. Despite other factors, both the data of male and female prove that more Filipinos are marrying in their twenties.

Since the respondents of the study are married couples, the distribution of the respondents according to gender is equal. There are 400 males and another 400 females which gives a total of 400 couples.

It was also evident from the obtained profile of the respondents that majority of the couples have not been together for more than ten years. Very few among them are engaged in marital relationship for several years. Moreover, it takes most of the couples until seven years before deciding to settle down. Adler in 2010 revealed that education of the couple affects the length of premarital relationship. When one opts to prioritize studies over marriage, then there will be longer premarital acquaintance [17]. However, if marriage interferes with education, this will result to shorter premarital acquaintance of the couples. Moreover, the status of the economy also affects this profile since poor economy will most likely delay marriage. This delay in marriage certainly leads to longer premarital acquaintance.

Quite a few couple respondents have none to two children, are Roman Catholic, are able to reach and graduate in high school and are belonging in the middle class.

The obtained data about the number of children is supported by the study of the Pew Research Center, confirming that today's couples do not view children as significant factors strengthening marriage. More individuals perceive children as problems than blessings. Thus, it is not surprising to realize that majority of the couples who took part in the study only have up to two children [18].

As for the religious affiliation, the data confirm that majority of the Filipino couples are of the same faith. It can also be observed from the table that most of the respondents are Roman Catholic, which is the dominant religion in the country. The other religions of the respondents included in the study are Born Again Christians, Iglesia ni Cristo, Jehovah's Witness and Protestants.

With regards to the educational attainment, even if the difference is not much great, it is still noticeable that women's educational attainment exceeds men's. This is supported by the studies done by Buchmann and DiPrete (2006), Schwartz and Mare (2005) and (Schwartz and Han, 2009) which state that in the recent years, women started to surpass men's educational attainment. This situation is the result of more opportunities for both men and women to study and receive formal education [19].

Considering the educational attainment and the employment status of the respondents of this study, it is not surprising to come up with the data which states that majority of the respondents belong to the middle class. Apart from it, the research locale included 11 municipalities, excluding the city. Thus, the covered areas are more than rural but less than urban areas.

As for the employment status, it was revealed that more men are employed than women even if the latter are receiving higher education as compared to men. Nonetheless, it can be noticed from the obtained data of the researchers that more Filipinas are starting to get a job also just like men.

Additionally, majority of the respondents exhibits significantly above average levels of the components of love, which are intimacy (49.5\% for male and $47 \%$ for female), passion (51.8\% for male and $45.5 \%$ for female) and commitment $(67.0 \%$ for male and $64.8 \%$ for female). A number of both male and female respondents were also found to experience satisfying marital relationship (90.8\% for male and $86.3 \%$ for female).

However, the components of love varied when the respondents were grouped according to their profile. The level of intimacy of male respondents varied when they are grouped to their age when married $\mathrm{F}(4,395)=2.915, p<.05$, $n^{2}=.03$. However, Turkey's post hoc procedure is not performed because at least one group has fewer than two cases. This result presumed that male respondents who married at older age (27 to 66 years of age) has developed higher level of intimacy compared to those who married at younger age (17 to 26 years of age) because they have already established their identity and are willing to share, trust, care, and accept which are ingredients to build intimate relationship.

According to Cox, there is greater risk of marital dissatisfaction and failure if the couples or one of the couples married at a younger age [15]. This finding points 
out the advantage of male respondents who married at older age over those who married at a younger age because they already established their self-concept or identity which brings about an experience of warmth and a desire to give and receive emotional support by sharing one's innermost thoughts with another through the feelings of closeness and connectedness toward the partner [7].

There are no variations on the level of intimacy of the male and female respondents when grouped according to gender, religion and employment status. The result assumes that there is equal level of intimacy on both male and female respondents despite the enumerated profile.

This indicates that most male and female respondents are able to play their various roles in marriage including their gender roles. If these roles were balanced, one may be able to have a better state of well being [15].

There is also equal level of intimacy when respondents are grouped according to religion most likely because most of the partners share the same religious belief. This directly maintains marital relationship including intimate relationship of partners due to the possible presence of familial, societal, and religious support [20].

Also, the researchers assumed that there is equal level of intimacy when respondents are grouped according to employment status because of acceptance on their roles wherein most male respondents work to support their family while most female respondents are plain housewives. This acceptance is one of the ingredients in building intimate relationship.

As for passion, there are no variations on the level of passion of the male and female respondents when grouped according to age, marrying age, length of marital acquaintance, educational attainment, length of premarital acquaintance, number of children, and socio-economic status. This connotes that there is equal level of passion on both male and female respondents despite the variation on the mentioned profile of the respondents. This indicates that the profile of the male and female respondents do not have great influence to their feelings of longing, desire, and excitement towards their partner in life. Since the couple are living together and have a chance to see each other at the end of the day, such intense longing for union with the particular other may have been easily resolved. Hence, couples are able to sustain their passion in their relationship. This is because they experiences strong emotional feelings (produced by PEA chemical) including those "tingling" sensations of excitement and euphoria [7] whenever they get to touch each other. Moreover, some married couples hold on to that passion and romance for decades or more because love take a rebirth with age and years based on new research featured in an article by Kachru. In addition, having children may replace sexual freedom or interferes with the couples' sex life; however, couples may plan their times together to have quality times with each other [13].

Moreover, employed male respondents $(M=111.00, S D$ $=20.68)$ had significantly higher level of passion than those unemployed male respondents $(M=105.20, S D=23.61)$, $t(398)=2.277, p<.05, d=0.27$. The researchers conclude that employed married men have higher level of passion toward their wife compared to unemployed married men for the reason that they perceived domination on their partner's life. Employment of man sustains his dominance over his partner's life which is considered by Lauer and Lauer (2007) as one of the characteristics of passionate love [9]. Hence, being employed of married men has small positive effect on their level of passion toward their wife.

Last for the components of love, there are significant differences on the level of commitment of the respondents based on the profile: educational attainment of female respondents and employment status of both male and female respondents.

The level of commitment of female respondents varied when they are grouped to their educational attainment $\mathrm{F}$ (5, $394)=2.915, p<.05, n^{2}=.03$. Tukeys post hoc procedure indicated that female respondents who attained college education $(M=123.61, S D=12.95)$ has significant higher level of commitment than female respondents who finished elementary education $(M=115.07, S D=24.24)$. Female respondents who attained college education have significantly higher level of commitment than female respondents who finished elementary education. Commitment which maintains the relationship through thick and thin (Sternberg, 2004) encourages one to do "prorelationship acts" or things that are good for the relationship which when perceived by the partner enhances the trust not only with the one doing the act but also in the relationship. As this feeling of trust increases, the partner's willingness to depend on the relationship also increases [7]; thus, the trust is a major element of commitment. According to Marano [21], trust may waver when jealousy trigger doubt and preoccupation with a partner's faithlessness; yet, jealousy points out more about the bearer than about the deeds or misdeeds of a mate. Those who are most insecure, in fact, may be most unrealistic in perceiving threats and making accusations. The researchers assume that female respondents who finished elementary education have lower self-esteem compared to those who attained college education. This brings about reduced level of self-worth which builds up their insecurities leading to jealousy. In contrast, a female respondent who is a college graduate may had developed sense of security wherein according to Lauer and Lauer [9], she regards jealousy as her own problem and not the fault of her partner for she knows that they are committed to each other. With this, the result indicates that higher educational attainment of female respondents increases the level of their commitment to their husband.

Employed male respondents $(M=122.99, S D=16.45)$ had significantly higher level of commitment to their wife than unemployed male respondents $(M=116.9011, S D=$ 21.32), $t(398)=2.90, p<.05, \mathrm{~d}=0.30$. On the other hand, employed female respondents $(M=118.79, S D=18.17)$ had significantly lower level of commitment to their husband than unemployed female respondents $(M=122.35, S D=$ 17.17), $t(398)=-2.005, p<.05, d=-0.20$.

Married men play the role of husband-father as the breadwinner of the family. If they are employed, there is a higher possibility that they will be able to provide the needs of his wife (including their children). Reference 19 affirmed that as the partners aspire to meet the needs of the other, commitment is developed. In addition, unemployment of men indicates less commitment because their perception of what marriage is supposed to was not met [22]. Moreover, 
unemployment of men which is unacceptable to many, threatens their gender identity and role congruence so regardless of their marital satisfaction, they are more likely to initiate divorce.

Married women as wife-mother play the expressive role in the family wherein they provide the emotional support and nurturing activities that ensure the household runs smoothly [23]. This role makes them economically dependent on their husbands. According to Christin Munsch, a sociologist, females who are more dependent on their male partners are less likely to engage themselves in infidelity. His study entitled "The Effect of Relative Income Disparity on Infidelity for Men and Women." found that "women who were completely dependent on their male partner's income were 50 percent less likely to cheat than women who made the same amount of money as their partner, and 75 percent less likely than women who contributed most or all of the household income." Women are not threatened even when they make less money or none at all because it is the status quo. In addition, economically dependent wife may perceive that cheating on their husbands is not worth to risk their livelihood [24]. Another support is that "fear of the social, financial, and emotional costs of the union breaking up" noted as a constraint is an element of commitment according to Adams \& Jones in 1997 [9]. Likewise, some women work in this changing society wherein feminism is thriving. This choice of women to join the workforce does not violate any marriage norms.

Being employed only gives women financial security [24]. The researchers assert that employed female respondents are less committed than unemployed female respondents for they will be able to support themselves whenever their husbands leave them or to leave when their relationship with their husband does not work. Moreover, Ms. Olive Diokno, one of the panelists on thesis defense, asserted that "probably because they [women] have work, they don't have much time also for the husband because they still have the children, household tasks to do."

It was found that employed male respondents $(M=$ $133.926, S D=1.12$ ) has significantly higher level of marital satisfaction than unemployed male respondents $(M=$ $128.901, S D=2.43), t(398)=2.051, p<.05, d=0.24$. Employed male respondents have significantly higher level of marital satisfaction than unemployed male respondents. Reference 4 stated that "an examination of the role that personal expectations play in marital success is perhaps more important than examination of a long list of factors that may or may not affect a particular couple's marital success." Definite assertion that marital expectations are strong predictor of the success or failure of a marital relationship, construe high level of marital satisfaction of employed male respondents. This is because male respondents who are employed may have reached the expectation of being the earner and provider in the family. In contrast, unemployed married men have low level of marital satisfaction because they were not able to achieve the expectation of their wives to provide their needs and make them feel fulfilled. This unmet expectation brings disappointment in marriage. The results imply that employment status of male respondents increases their satisfaction in their marital relationship.
Lastly, the components of love have significant positive relationship with the marital satisfaction of all the respondents. On both male and female respondents, intimacy has a very strong positive relationship with marital satisfaction while passion and commitment have strong positive relationship with marital satisfaction. This indicates that when the levels of intimacy, passion, and commitment increases or decreases individually, marital satisfaction of the respondents also increases or decreases, respectively and vice versa. This signifies the undeniable importance of love in marital relationship. If couples consider the combination of the three components namely intimacy, passion and commitment or termed as consummate love by Sternberg, there is a great possibility of achieving a lasting marital satisfaction.

\section{ACKNOWLEDGMENT}

The researchers would like to acknowledge the following persons, for their kindness and generosity in offering us help without expecting anything in return, for giving us their time and sharing their knowledge and expertise to bring out the best in this research: Dr. Janette Funk (who allowed us to use their test CSI-32), Mr. Romil Silva (translator of the test used in the research), Ms. Lerma Ilao (statistician), Dean Tessie Palma, Ms. Olive Diokno, and Mr. Wilmer Adajar (panellists), Ms. Romaine Magboo (thesis adviser), Mr. Darwin Magpili (teacher-in-charge), the mayors of the covered municipalities in this study so as all the persons who helped us gather the necessary data from a myriad of respondents, and most especially, the respondents who took part in this study.

\section{REFERENCES}

[1] D. G. Myers, Social Psychology, 8th ed., New York: The McGrawHill Companies, Inc., 2005.

[2] Number and percent distribution of marriages of bride and groom by region. (August 2006). [Online]. Available: http://www.census.gov.ph/data/sectordata/2003/ms0301.htm

[3] R. D. Cruz, "Fewer Filipino couple getting, staying married," Manila Standard Today, pp. A1, A2, February 2008.

[4] R. J. Sternberg. (1997). Construct validation of a triangular love scale. European Journal of Social Psychology. [Online]. 27. pp. 313-335. Available: http://web.comhem.se/u68426711/8/sternberg97.pdf

[5] J. L. Funk and R. D. Rogge, "Testing the ruler with item response theory: Increasing precision of measurement for relationship satisfaction with couples satisfaction index," Journal of Family Psychology, pp. 572-583, 2007.

[6] A. V. Panganiban, "The rings of a happy marriage," Philippine Daily Inquirer, p. A13, September 2007.

[7] S. A. Rathus, J. S. Nevid et al., Human Sexuality in a World of Diversity, Boston: Pearson Education, Inc., 2011.

[8] T. P. Tung. (2007). Romantic relationship: Love styles, triangular love and relationship satisfaction. City University of Hong Kong. [Online]. Available: http://lbms03.cityu.edu.hk/oaps/ss2007-4708tpt530.pdf

[9] R. Lauer and J. Lauer, Marriage and Family: The Quest for Intimacy, McGraw-Hill Higher Education, 2007

[10] S. L. Franzoi, Social Psychology, 5th ed., New York: McGraw-Hill Companies, Inc., 2009.

[11] G. Feist and J. Feist, Theories of Personality, $7^{\text {th }}$ ed., Singapore: McGraw-Hill, Inc., 2009.

[12] R. F. Baumester and B. J. Bushman, Social Psychology and Human Nature, Wadsworth: Cengage Learning Academic Resource Center, 2011.

[13] Clifford and J. Penner. (2012). Keeping the spark of your 'first love'. [Online]. Available: http://family.pepperdine.edu/marriage/articles/marriage/romance/keep ing-spark-first-love.htm 
[14] C. A. Anonuevo. (September 2000). An overview of the gender situation in the Philippines. Friedrich-Ebert-Stiftung Philippine Office. [Online]. Available: http://library.fes.de/pdffiles/bueros/philippinen/50069.pdf

[15] F. D. Cox, Human Intimacy: Marriage, the Family, and Its Meaning, United States of America: Thomson Learning, Inc., 2006.

[16] Census of population and housing (Batangas). (2010). National Statistics Office, Republic of the Philippines. [Online]. Available: http://www.census.gov.ph/data/sectordata/2010/2010CPH_reg4a.pdf

[17] F. Adler, Marriage and Divorce, BiblioBazaar: 2010.

[18] Pew social and demographic trends. (July 2007). Pew Research Center. [Online]. Available: http://www.pewsocialtrends.org/2007/07/18/modern-marriage/

[19] C. R. Schwartz and H. Han, "Trends in the gender education gap in marriage and marital dissolution," United States of America: Wisconsin-Madison, September 2009

[20] B. M. Scott and M. A. Schwartz, Marriages and Families, New Jersey: Pearson Education, Inc., 2007.

[21] H. E. Marano. (March 2012). Jealousy: love's destroyer. PsychologyToday. [Online]. Available: http://www.psychologytoday.com/articles/200906/jealousy-lovesdestroyer.

[22] Men more likely to cheat if they are economically dependent on their female partners, study finds. (August 18, 2010). Science Daily. [Online]. Available: http://www.sciencedaily.com/releases/2010/08/100816095617.htm

[23] L. L. Lindsey. (2005). The sociology of gender: theoretical perspectives and feminist frameworks. Gender Roles: A Sociological Perspective. [Online]. $\quad$ pp. $6 . \quad$ Available: http://www.pearsonhighered.com/assets/hip/us/hip_us_pearsonhigher ed/samplechapter/0132448300.pdf

[24] C. Munsch. (August 2010). Men more likely to cheat if they are economically dependent on their female partners. American Sociological Association. [Online]. Available: http://www.asanet.org/press/infidelity_and_income.cfm

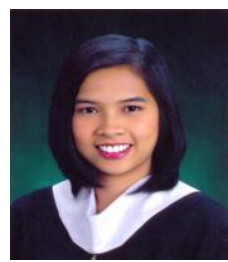

psychologist. As part of the curriculum, she had her practicum as an intern in Panganlungan Halfway House Rehabilitation Center in Batangas, a guidance associate at St. Bridget College Batangas and assistant in Balayan Distillery, Inc. Batangas. Currently, she is a teacher at Stonyhurst Southville International School.

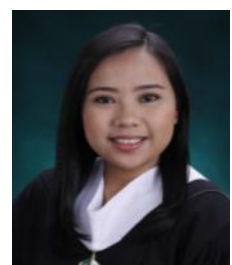

Isabel Vivien P. Guda is a psychology graduate of De La Salle University-Lipa. She has been a member of Psychological Association of the Philippines Junior Affiliates, taking part in the seminars and activities spearheaded by the said organization for the growth in knowledge in the field of psychology. She earned her degree BS Psychology last April 2013.

In the previous years, she has experienced working in the three fields of psychology, working as an intern in Panganlungan Halfway House Rehabilitation Center in Solo, Mabini Batangas, a guidance associate at St. Bridget College Batangas and assistant to the Quality Assurance Officer, Training Officer and Customer Service at St. Patrick's Hospital Medical Center. 